\title{
A teacher's learning process in dual design research: learning to scaffold language in a multilingual mathematics classroom
}

\author{
J. Smit • H. A. A. van Eerde
}

Accepted: 2 July 2011 / Published online: 26 July 2011

(C) The Author(s) 2011. This article is published with open access at Springerlink.com

\begin{abstract}
In this paper, we argue that dual design research (DDR) is a fruitful way to promote and trace the development of a mathematics teacher's expertise. We address the question of how a teacher participating in dual design research can learn to scaffold students' development of the language required for mathematical learning in multilingual classrooms. Empirical data were collected from two teaching experiments (each with 8 lessons, and 21 and 22 students, aged 11-12 years), for which lesson series about line graphs were co-designed by the researchers and the teacher. The teacher's learning process was promoted (e.g. by conducting stimulated recall interviews and providing feedback) and traced (e.g. by carrying out 5 pre- and post-interviews before and after the teaching experiments). An analytic framework for teachers' reported and derived learning outcomes was used to analyse preand post-interviews. The teacher's learning process was analysed in terms of changes in knowledge and beliefs, changes in practice and intentions for practice. Further analysis showed that this learning process could be attributed to the characteristics of dual design research, for instance the cyclic and interventionist character, the continuous process of prediction and reflection that lies at its heart, and the process of co-designing complemented with stimulated recall interviews.
\end{abstract}

Keywords Design research - Scaffolding language · Mathematics teacher's expertise $\cdot$ Multilingual classrooms

J. Smit $(\bowtie) \cdot$ H. A. A. van Eerde

Freudenthal Institute, Utrecht University,

Princetonplein 5, 3584 CC Utrecht, The Netherlands

e-mail: J.Smit1@uu.nl

H. A. A. van Eerde

e-mail: H.A.A.vanEerde@uu.nl

\section{Introduction}

Mathematics teachers' expertise can be improved in multiple ways. Teachers can collaborate on improving lessons, such as in lesson studies, with minimal help from outside experts (Stigler and Hiebert, 1999). In contrast, professional development can also be completely expert driven. In between these extremes, there are various forms of collaboration between researchers and teachers that lead to enhanced expertise, such as co-teaching (Roth, Tobin and Zimmermann, 2002), action research (Jaworski, 1998), learning studies (Ling Lo, Marton, Fai Pang and Yan Pong, 2004), teacher development experiments (Simon, 2000), teaching experiments (Norton and McCloskey, 2008) and design research (Brown, 1992; Collins, 1992; Gravemeijer and Cobb, 2006).

When comparing approaches such as lesson studies, learning studies and design research, it is apparent that their core is a process of predicting and reflecting. Secondly, these approaches do not only aim to produce effective lessons, but also to involve teachers in understanding why and how learning processes develop. Thirdly, the professional development activities take place in the context of the classroom. Fourthly, it is believed that only gradual improvement in teaching results in real change. Of course, there are also differences between the approaches. For example, design research as we envision it intends to develop theory on innovative forms of learning more explicitly than, say, lesson studies.

In this paper, we argue that design research can be a fruitful environment for mathematics teachers to develop their expertise. So far, very little is known about what and how a teacher can learn from participating in design research. Only a small minority of design research projects focus on teachers' learning, for instance by looking at 
professionalisation of groups of teachers operating in the institutional setting of the schools and district in which they work (Cobb, Zhao and Dean, 2009). The vast majority of design research studies focus on innovative types of learning by students, and in several cases the teaching is done by experienced researchers (Cobb, 2000). In this type of design research, the teacher's learning is not explicitly investigated. However, if we want teachers to be able to adapt instructional approaches to their own classroom practices, they need to know how these approaches work. To gain insight into such learning processes of teachers, Gravemeijer and Van Eerde (2009) plead in favour of dual design research (DDR), which aims to study the learning of students and their teacher within the same study.

Dual design research fits our research topic, scaffolding language development in multilingual mathematics classrooms, for two reasons. Firstly, scaffolding is a relational notion, as it is performed by a teacher to promote students' learning. Secondly, in scaffolding research, the area of scaffolding the language that is required for mathematical learning still needs development of theory and instructional activities. Therefore, it makes sense to start with smallscale innovative design studies as the basis for larger-scale professional teacher development. Although we investigated students' learning processes as well as those of a teacher in our design study, in this paper we focus on the latter. The goal of this paper is to gain insight into how a teacher participating in dual design research can learn to scaffold students' development of the language required for mathematical learning in multilingual classrooms.

\section{Theoretical background}

\subsection{Integrating mathematics and language development}

Dealing with ethnic and linguistic diversity is one of the major challenges of today's mathematics education (Campbell, Adams and Davis, 2007; Moschkovich, 2002). A 6-year study in the Netherlands (Van den Boer, 2003) has shown that ineffective teaching and learning practices in multilingual classrooms cause this problem to remain hidden and thus to persist. A common teacher practice is to avoid linguistic aspects of teaching, for instance by decontextualising context problems and avoiding time-consuming verbal interaction. A common student practice is to focus on mathematical calculations, considering text and context as of little importance. In addition, students tend not to ask questions. There seems to be only one way out of this double bind: to explicitly pay attention to the language needed for mathematical learning.

More generally, approaches of content-based language instruction (Brinton, Snow and Wesche, 2003) argue that teachers throughout the curriculum need to be prepared to teach content effectively while developing students' language ability. Presumably, such an approach to mathematics education creates opportunities to develop the required content-based (subject-specific) language, as a result of which mathematics lessons can become more accessible for all students. In the Netherlands, a few explorative studies have specifically focused on developing such an approach for mathematics (e.g. Van Eerde and Hajer, 2009), but these have had a limited effect: even if teachers learnt to give students linguistic support, they quickly fell back on old habits. This is hardly surprising, knowing that teachers in the context of educational innovation easily fall back on old routines, even after a considerable period of time and change (Verloop, Van Driel and Meijer, 2001). Hence, an explicit focus on developing teacher expertise for promoting language development in multilingual classrooms is needed.

\subsection{Scaffolding language}

One key strategy to foster language development in multilingual mathematics classrooms is scaffolding language (Gibbons, 2002). Drawing on the original definition of scaffolding (Wood, Bruner and Ross, 1976), Gibbons defines scaffolding as temporary, intentional, responsive support that assists second language learners to move towards new skills, concepts or levels of understanding. She places this notion in the context of classroom discourse and argues that bilingual students cannot build on the foundations of the second language as can native speakers. To develop the more academic registers necessary for participating in different areas of the curriculum, scaffolding subject-specific language is needed. She argues that education should help students to bridge discourses: from their initial most spoken-like (or context-embedded) language to most written-like (or context-reduced) language. The latter mode is presumed necessary to fully participate in a particular school subject. A design heuristic she offers to accomplish this is the 'teaching and learning cycle' (Gibbons, 2009). This cycle consists of a series of four stages in which a particular text type needed at school is introduced, modelled, jointly practised and eventually individually performed.

For this study, we identified a text type, a so-called 'target text', for the mathematical domain of line graphs, namely the interpretative description of a line graph (Fig. 1). Throughout all stages of the teaching and learning cycle, the teacher can perform designed scaffolding strategies (planned support) and interactional scaffolding strategies (unplanned support). Examples of designed scaffolding strategies include using a subject-specific word list, a writing plan for students, as well as modelling exercises that scaffold the students towards understanding the purpose, overall 


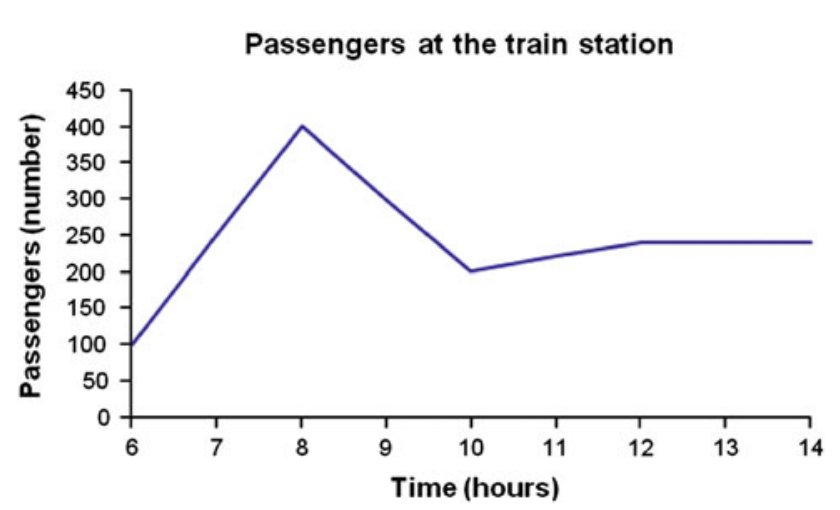

At 6 o'clock there are about 100 passengers at the train station. Between 6 and 8

o'clock, the number of passengers rises, for the graph shows a steep increase. At 8

o'clock, the number of passengers gets to its maximum: about 400. After that time, till

10 o'clock, the number of passengers drops. The graph descends. After 10 o'clock the

number of passengers slowly rises again; the graph shows a gradual increase. After

12 o'clock the number of passengers stays more or less the same. You can tell as the

graph is constant

Fig. 1 Line graph and example of a written target text

structure and language features of the chosen target text. Examples of interactional scaffolding strategies include repeating correct subject-specific utterances and reshaping what students say or suggest writing down.

\subsection{Required expertise}

Judgement of which scaffolding strategies to use in which situations requires a particular expertise. In the teaching literature, it is very common to conceptualise teacher expertise in terms of pedagogical content knowledge (Shulman, 1987), and modifications of pedagogical content knowledge, such as knowledge of content and teaching (Ball, Thames and Phelps, 2008). However, many scholars studying pedagogical content knowledge stress its lack of definition and empirical foundation (Ball et al., 2008; Graeber and Tirosh, 2008). In line with Mason (1998), we find it more useful to focus on awareness as a starting point for a teacher who is learning, in our case to scaffold. According to Mason, awareness is manifested in alterations in the structure of a teacher's attention. In the context of our research, this implies that the ability to shift attention between the main foci-here mathematics and the language needed for mathematical learning-represents a certain awareness that is needed to actually realise scaffolding. Of the three layers of awareness Mason distinguishes, awareness-in-action best fits our study, because it is the type of awareness that makes certain actions possible.

Based on the literature (e.g. Mason, 2010), we assume awareness to be interrelated with intentions, emotions, knowledge and beliefs. Awareness of students' linguistic problems seems to be a basis for the intention and desire to scaffold students, but these are also based on the belief that it is possible to do so. Enacting scaffolding requires sensitivity to students, which Potari and Jaworski (2002, pp. 352-353) define as "the teacher's knowledge of students and attention to their needs." Such enactment requires knowledge of scaffolding strategies and of the conditions for, and consequences of, applying them. Such diagnostic and responsive knowledge we assume, in turn, increases teachers' awareness of students' linguistic problems. However, awareness as part of teacher expertise is difficult to operationalise. For these reasons, we propose to include attention to knowledge, beliefs, intentions and emotions in our analysis of teachers' developing expertise.

\subsection{Our approach to developing teacher expertise}

As noted by Bakkenes, Vermunt and Wubbels (2010), several types of learning activities keep returning in the literature on developing teacher expertise:

1. Learning by experimenting (e.g. trying out a new teaching method; making new materials),

2. learning in interaction with others (other teachers, researchers),

3. using external sources (e.g. publications),

4. consciously reflecting on one's own teaching practices.

Reflection is frequently mentioned as crucial for expertise development (Ropo, 2004). Revans (1982) argues that reflection implies looking forward as much as backward. It means asking questions about one's own practice and foreseeing possibilities for change and development.

Any approach to developing teacher expertise should thus capitalise on these four teacher learning activities, and many of the approaches to developing teacher expertise mentioned in our introduction indeed do. In the remainder of this section, we explain how we stimulated these learning activities by involving a teacher in our design research project, and why we chose dual design research as the method suitable for our research purpose of gaining insight into how scaffolding can be performed and learnt.

By involving the teacher in design research, she was not only experimenting in the classroom (1), but also interacting with us as the researchers (2). In this co-design process, we provided her with external sources (3) such as aforementioned key publications about scaffolding and linguistic problems in multilingual classrooms. As we explain in more detail in Sect. 3, we used the co-design process in combination with stimulated recall interviews (Meijer, Zanting and Verloop, 2002) to promote reflection (4).

Our arguments for using design research are as follows. In line with our research purpose, design research as 
envisioned by Cobb et al. (2003) aims at developing innovative materials and theories. Scaffolding language is not typically done in current mathematics classrooms. Enacting it requires an educational innovation that should in our eyes be accompanied by the development of new theories-layered from insights into what students learn from scaffolding strategies that can be performed to insights into how a teacher can learn to perform these strategies. Whereas in lesson and learning studies, for example, the main goal is to achieve particular educational objectives, our initial main focus was the theoretical grounding of scaffolding. Because we did not exactly know at the start of the research project how a teacher could scaffold language in mathematics classrooms, we initially worked intensively with one expert teacher.

Furthermore, the different layers of theory development in design research fit our research purposes well. As design research studies ways to support learning, it allows us to develop theoretically the notion of scaffolding while at the same time enhancing and developing its enactment in real classroom situations. In the case of employing a wellknown notion (scaffolding) in a less well-known context (multilingual mathematics classrooms), it is essential to study to what extent students actually benefit from those scaffolding strategies and, more importantly, how they benefit from them. Simultaneously, design research wishes to involve the teacher in trying to understand why and how students' learning processes develop. In this study, we additionally attempted to promote and study the teacher's own learning process. For that reason, we chose to conduct dual design research (Gravemeijer and Van Eerde, 2009), a special case of design research, combining the study of student learning and teacher learning.

In this paper we intend to shed light on a mathematics teacher's learning process in dual design research. More specifically, we address the following questions:

1. What can a teacher participating in dual design research learn in terms of scaffolding students' development of the language required for mathematical learning?

2. To what characteristics of dual design research can the participating teacher's learning process be attributed?

\section{Methods}

\subsection{Setting and students}

Two teaching experiments were carried out in the last two grades of two suburban primary schools (with students of age 10-12 years). In the first teaching experiment, 4 of the 22 students spoke Dutch as a second language and at least half of the class could be considered students with low language proficiency. After the first cycle, we considered the notion of scaffolding elaborated enough to enact and study in a genuinely multicultural setting. The number of students speaking Dutch as a second language in the second teaching experiment was 20 out of 21 , the majority being second- and third-generation Moroccan and Turkish students, who performed rather weakly on a standardised test for language (CITO assessment). For each teaching experiment, the researchers, in collaboration with the teacher, designed eight lessons in the domain of line graphs, according to the teaching and learning cycle described earlier (Gibbons, 2009). Lessons were given once a week and lasted around $60 \mathrm{~min}$.

\subsection{Participating teacher}

The participating teacher, Lara (pseudonym), had 16 years of experience in primary education, partly in multilingual classrooms. At the time of the teaching experiments, she was appointed as an expert mathematics teacher at the primary school she was working at, which included preparing and evaluating mathematics lessons with her colleagues.

Although Lara was to a certain extent already familiar with second language learning issues, she had no experience with scaffolding. Throughout the experiments, Lara showed engagement and a will to learn. She had strong beliefs about good mathematics teaching, but we came to know her as an involved, critical discussion partner, willing to change her view when exposed to convincing arguments.

Lara was not familiar with the students in the classrooms she was working in during the teaching experiments; she entered these classrooms as a primary teacher participating in a research project. We presumed that the advantages of working with an expert teacher would outweigh the disadvantages of her being an outsider. For her to become familiar with the situated norms and rules, and to get to know the students, she observed several lessons beforehand.

\subsection{Instruments}

As we conducted dual design research, the instruments we used to promote learning served the students or Lara or both. The first instrument, having a double function, is the hypothetical learning trajectory (Simon, 1995) for each lesson. It consisted of mathematical and linguistic learning goals, a description of students' prior knowledge, and assumptions about how the instructional activities and scaffolding strategies would support their learning processes. In line with the learning activities mentioned in Sect. 2.4 (experimenting, interaction and reflection), we involved Lara in the formulation of each hypothetical learning trajectory and reflected with her on how well it matched students' learning in the previous lesson. Thus the hypothetical learning trajectory 
formed the core of the co-designing process of the teacher and the researchers, providing them with a shared lens through which lessons were designed and evaluated.

The second instrument, used to promote the teacher's learning process, consisted of reflective interviews with the teacher in between lessons, which were increasingly systematised. In the first teaching experiment, after each lesson we had discussions with her, in which different scaffoldingrelated topics were discussed with no pre-structured order imposed. In the second teaching experiment, we conducted stimulated recall interviews with the teacher after each lesson, following a set order of question types. For instance, we always started by asking the teacher neutral questions when watching video tapes of the lesson just given, such as: "What happens here? What do you observe when watching this fragment?" The idea behind this approach is to stimulate the teacher to think out loud, and thus to stimulate her to relive the lesson (Meijer et al., 2002). In this way, we presumed to promote reflection and thus increase her awareness.

Instruments to trace the teacher's learning process included written interview schemes for pre- and postinterviews, used to determine her initial expertise, as well as the development of her scaffolding expertise. A written post-post-interview scheme was used to gain insight into the aspects of her learning environment to which she attributed her learning process.

\subsection{Data collection}

Data collection included audio and video recordings of all lessons, field notes, students' pre- and post-test results as well as their written work. We also collected our e-mail correspondence with the teacher. In the second teaching experiment, we asked the teacher to also write reflective reports after each lesson. In this way, we hoped to promote her learning process and gain more insight into her thought processes. Furthermore, two pre-interviews, two post-interviews, and one post-post-interview with the teacher were audio-recorded, as were reflective conversations and stimulated recall interviews. All interviews were transcribed (Table 1).

\subsection{Data analysis: what did Lara learn?}

In the analysis, we initially focused on the first research question: what did the teacher learn in terms of scaffolding language? To find an answer to this question, we have analysed both self-reported and derived learning outcomes.

To identify Lara's reported learning outcomes, we employed the four main categories from an analytic framework for teachers' reported learning outcomes, introduced by Bakkenes, Vermunt and Wubbels (2010): (1) changes in knowledge and beliefs, (2) intentions for practice, (3) changes in practice and (4) changes in emotions. Bakkenes et al. used this framework to analyse teachers' learning in the context of a national innovation programme across all school subjects and found it a valid and reliable instrument. We used these categories (as summarised in the descriptions of Table 2) as the main categories in our coding scheme. In Table 2, these categories are shown, as well as examples for each category.

In the transcripts of the first post-interview, the second pre-interview and the second post-interview, all utterances

Table 1 Timeline showing dates of interviews and teaching experiments

\begin{tabular}{lllllll}
\hline 20 July 2009 & Sept.-Nov. 2009 & 08 Dec. 2009 & 18 Feb. 2010 & March-Apr. 2010 & 27 Apr. 2010 & 27 Oct. 2010 \\
\hline $\begin{array}{l}\text { First pre- } \\
\text { interview }\end{array}$ & $\begin{array}{c}\text { First teaching } \\
\text { experiment }\end{array}$ & $\begin{array}{c}\text { First post- } \\
\text { interview }\end{array}$ & $\begin{array}{c}\text { Second pre- } \\
\text { interview }\end{array}$ & $\begin{array}{c}\text { Second teaching } \\
\text { experiment }\end{array}$ & $\begin{array}{c}\text { Second post- } \\
\text { interview }\end{array}$ & $\begin{array}{c}\text { Post-post- } \\
\text { interview }\end{array}$ \\
\hline
\end{tabular}

Table 2 Coding scheme for reported learning outcomes

\begin{tabular}{|c|c|c|}
\hline Code & Description & Examples \\
\hline $\mathrm{ckb}$ & $\begin{array}{l}\text { Change in knowledge/belief: the teacher reports on growing } \\
\text { awareness, acquired knowledge, new ideas; or the teacher reports on } \\
\text { confirmation of already existing beliefs }\end{array}$ & $\begin{array}{l}\text { I think I am now more aware that these children need to hear } \\
\text { new concepts ten times more often than their native-speaking } \\
\text { peers }\end{array}$ \\
\hline $\mathrm{cp}$ & $\begin{array}{l}\text { Change in practice: the teacher states that things have changed in her } \\
\text { way of teaching or reports on a change in her way of coaching other } \\
\text { primary teachers }\end{array}$ & $\begin{array}{l}\text { Right now I focus more on teaching children how to write in } \\
\text { maths lessons }\end{array}$ \\
\hline ip & $\begin{array}{l}\text { Intention for practice: the teacher reports that she wants to do things } \\
\text { differently in the future, or reports that the research setting provided } \\
\text { her with the insight that she wants to hold on to certain old practices }\end{array}$ & $\begin{array}{l}\text { I really want to be more alert to students' precise use of } \\
\text { language }\end{array}$ \\
\hline ce & $\begin{array}{l}\text { Change in emotions: the teacher reports on emotions related to the } \\
\text { experimental lessons, or reports on being surprised ("unexpected } \\
\text { events") }\end{array}$ & $\begin{array}{l}\text { As a result of these lessons, I now feel much more secure when } \\
\text { it comes to teaching multilingual students }\end{array}$ \\
\hline
\end{tabular}


in which Lara explicitly reports on a learning outcome were identified and coded by one researcher. Two independent raters coded a subset of utterances to determine the interrater reliability of the coding process. The $2 n^{2}$ rule (Cicchetti, 1976) was used to determine the number of fragments in this subset. This rule implies that for a reliable interpretation of a computed kappa, the number of fragments should be $2 n^{2}$ or more, where $\mathrm{n}$ is the number of codes. Because $n=4$ in our case, 32 fragments $\left(2 \times 4^{2}\right)$ were used. This resulted in 30 agreements in coding $(93.7 \%$; Cohen's kappa $=.91)$, meaning that the four categories could be reliably distinguished.

After conducting this analysis, we felt the need to conduct another analysis to gain insight into the nature of the reported learning outcomes. Within each category except emotions, we placed all utterances in chronological order. This chronological ordering helped us gain insight into changes over time. However, we also conjectured that the reported learning outcomes only formed the tip of the iceberg. We therefore also derived learning outcomes from Lara's statements by comparing utterances in the successive interviews in search of (non-reported) changes. This proved meaningful only for the category of knowledge and beliefs. We have not found any derived learning outcomes that contradict reported learning outcomes.

As a last step in the analysis of learning outcomes, we categorised all reported and derived learning outcomes representing changes in knowledge and beliefs (105 in total) into five thematic categories: (1) relation between language and thinking mathematically; (2) the writing of a target text in the domain of line graphs; (3) scaffolding language in mathematics education; (4) learning how to scaffold language; (5) students' language development and participation.

The first author conducted the analysis, leading to both a summary of changes in practice and intentions for practice, as well as a summary for changes in knowledge and beliefs, specified for each formulated theme. Based on her reading of the thematically and chronologically ordered data, the second author validated these summaries. She judged each conclusion drawn by the first author to be valid. She only suggested two minor reformulations.

\subsection{Data analysis: to what characteristics of dual design research can Lara's learning process be attributed?}

In the pre- and post-interviews we conducted, Lara expressed hardly any statements as to what she attributed her own learning process. When she did, she did so in very general terms, as in the utterance expressed just after finishing the second teaching experiment: "I have thought about mathematics and language for about ten weeks and well, that is quite something. It really makes you think about it all." In a telephone call several months after finishing the second teaching experiment, Lara declared: "This is the first time [in my life] I have actually really learnt something from professional development." This statement induced us to conduct a post-post-interview so that we could understand her own view on and explanations for her learning.

We decided to split the post-post-interview into a written part, to allow Lara time to think carefully before answering, as well as a verbal part, to allow ourselves to get back to Lara's written answers. In the written part, one of the things we asked Lara was to determine on a fivepoint scale ( 1 meaning very unimportant; 5 meaning very important) how she valued different aspects of her learning environment, and to explain the attributed ratings. These aspects (18 to be rated in total) included reflecting on instructional activities and relating them to pre-determined lesson goals, feedback on scaffolding strategies, reading and discussing literature, as well as stimulated recall interviews. In the verbal part of the post-post-interview, we asked Lara to further elaborate on some of her answers from the written part of the interview.

\subsection{Data analysis: illustrating the characteristics of dual design research}

In an attempt to identify the aspects of Lara's learning environment (the dual design research setting) that might have enhanced her learning, we focused on the enactment of an exemplary scaffolding strategy, namely the interactive use of an 'expanding word list'. We chose this scaffolding strategy because Lara only managed to perform this strategy in one of the final lessons in the second teaching experiment. We presumed that specific characteristics of dual design research, as carried out in the two teaching experiments, were crucial for Lara's accomplishment. To determine to which of these characteristics Lara's learning can be attributed, we analysed all relevant written data, including reports of reflective discussions, transcripts of stimulated recall interviews and Lara's reflective notes. These findings were supported by triangulating them with our analysis of video fragments, in which Lara enacted the word list scaffolding strategy. These fragments also served to analyse whether and how Lara fine-tuned her use of the word list.

\section{Results}

4.1 What did Lara learn with respect to scaffolding language?

The majority of reported learning outcomes fell in the category of knowledge and beliefs (33 utterances in total). Changes of practice were reported 27 times; intentions for 
Table 3 Distribution of reported learning outcomes among four categories

\begin{tabular}{llll}
\hline & $\begin{array}{l}\text { First post- } \\
\text { interview } \\
\text { (post1) }\end{array}$ & $\begin{array}{l}\text { Second pre- } \\
\text { interview } \\
\text { (pre2) }\end{array}$ & $\begin{array}{l}\text { Second post- } \\
\text { interview } \\
\text { (post2) }\end{array}$ \\
\hline $\begin{array}{l}\text { Changes in } \\
\text { practice }\end{array}$ & 7 & 8 & 12 \\
$\begin{array}{c}\text { Intentions for } \\
\text { practice }\end{array}$ & 2 & 6 & 4 \\
$\begin{array}{c}\text { Changes in } \\
\text { knowledge and } \\
\text { beliefs }\end{array}$ & 11 & 6 & 16 \\
$\begin{array}{c}\text { Changes in } \\
\text { emotions }\end{array}$ & 0 & 1 & 1 \\
\hline
\end{tabular}

practice were reported 12 times. Notable is the rarity of changes in emotions: these were only reported twice. We therefore exclude this category from the analysis of changes. Table 3 shows the distribution of utterances among the used categories (changes in practice, intentions for practice, changes in knowledge and beliefs, and changes in emotions) for three interviews. For instance, the table shows that the second post-interview contained the highest amount of changes in knowledge and beliefs (16) as well as the highest amount of changes in practice (12). This suggests that it was not until the second teaching experiment that Lara developed a deeper knowledge and a more fluent performance of scaffolding, resulting in a higher amount of reported learning outcomes than reported after the first teaching experiment (interviews post1 and pre2).

In the next subsections, we will present quotes to illuminate Lara's development over time. First, we will do so for reported changes in practice and intentions for practice (Sects. 4.1.1 and 4.1.2). Secondly, we will describe the development of changes in knowledge and beliefs (Sect. 4.1.3), concerning not only the reported learning outcomes as mentioned in Table 3 , but also derived learning outcomes (all of these classified into the 5 thematic categories mentioned before). A summary of these findings is presented in Table 4.

\subsubsection{Changes in practice}

Below, some utterances containing reported changes in practice are cited. We indicate from which interview these were cited in parentheses.

I think I ask much more for precise formulations, what the name is of different things... (post1)

I now actually have to formulate grammatically correct myself too. And I do not think I was that alert on formulating in the past. I am getting much more precise now. (post1)

What I always do now when coaching other teachers, while we are..., while jointly preparing their maths lessons, is asking them:

- Which words does the exercise book use?

- Do we consider those words useful?

- Do those words constitute mathematical language?

- Which comparable words do we use in daily language?

- Which words do the students already know?

- In which [mathematical] situations do students use the words they already know?

So in that sense, I am much more aware of the language to be used. (pre2)

Only now do I think it is really important that students learn to describe a line graph and tell what it stands for and with respect to that I think... I do not think I did that in the past. (post2)

Look, I did focus on vocabulary in the past [at multilingual schools], but now I think these were actually

Table 4 Lara's development over time as deducted from reported and derived learning outcomes

\begin{tabular}{|c|c|}
\hline & Summary of developments over time \\
\hline Changes in practice & $\begin{array}{l}\text { Lara first became aware of the use of precise, content-specific language by the pupils as well as by herself. } \\
\text { Subsequently, she shared this insight with other teachers supervised by her. Later on, she started to stress the } \\
\text { importance of the functional and integrated use of language in mathematics lessons }\end{array}$ \\
\hline Intentions for practice & $\begin{array}{l}\text { At first, Lara's intentions were only related to formulating more precisely. From the second pre-interview onwards, } \\
\text { the variety of intentions increased. Moreover, Lara's intentions also started to include statements on how to } \\
\text { develop a teacher's ability to scaffold }\end{array}$ \\
\hline $\begin{array}{l}\text { Changes in knowledge and } \\
\text { beliefs }\end{array}$ & $\begin{array}{l}\text { Lara developed the belief that language production in general and writing in particular should be more prominent } \\
\text { in mathematics lessons. Furthermore, Lara became more aware of: } \\
\text { The difficulty and necessity of adequately performing scaffolding strategies in multilingual classrooms; } \\
\text { Multilingual students' hidden linguistic incompetence and the need for them to participate actively and produce } \\
\text { content-specific language }\end{array}$ \\
\hline & Furthermore, Lara's knowledge of scaffolding strategies expanded \\
\hline
\end{tabular}


waffling-on kind of lessons...I am now much more focused on integrating language and mathematics. (post2)

The first two fragments represent Lara's newly gained focus on formulating precisely and correctly (first postinterview). The fragments from the second pre-interview indicate further development. The multifacetedness of the questions she poses to other teachers whom she supervises shows her ability to apply the idea of different modes of discourse and the corresponding types of language. When looking at fragments from the second post-interview, we observe that the reported changes in practice now concern the functional use of language in mathematics lessons.

\subsubsection{Intentions for practice}

When looking at reported intentions for practice, we observe a comparable enrichment. Where Lara's expressions in the first post-interview only focused on paying more attention to formulating precisely, the variety of reported intentions for practice did increase from the second pre-interview onwards. Examples include the intentions: to be more explicit when it comes to using and reinforcing mathematical key concepts; to experiment with different organisation forms aiming at students' oral language production; to better integrate language in mathematics lessons. Notable too are Lara's intentions in the second post-interview, as here she started to include intentions of what conditions allow her to realise the performance of scaffolding strategies:

On the other hand, it is needed to also experiment with strategies from which at first I thought 'does this make me happy?' Even if something, like reformulating utterances, was not really my style, I started to see the benefits of this strategy for the students. So...so I do need to try things out. (pre2)

I really want to practise more often [to perform scaffolding strategies], as I do realise that's what I need. (post2)

I do realise that...I want to more look for ways of implementing scaffolding strategies in other mathematical domains too. (post2)

\subsubsection{Changes in knowledge and beliefs}

Changes in knowledge and beliefs primarily concerned the theme relation between language and thinking mathematically. The most notable change was found in Lara's belief on the significance of mathematical content and language development in mathematics lessons. Before the start of the first experiment, Lara stated that mathematical content should be predominant in mathematics lessons, as is apparent in the utterance "so I think, when talking about graphs, the most important focus should be on what is the graph's mathematical structure". After the second teaching experiment, Lara stated: "You always need to talk about language first; only then you can start teaching mathematics." In the same interview she stated:

I became more aware of that. I mean that language...should not be separated. You actually need language to do mathematics. So we are not going to practise words without context, but when a word appears in a whole-class discussion, then we focus on it. You have to integrate it, so that discussing words...eehm, becomes functional.

Within the theme writing of a target text in the domain of graphs, we encountered some critical statements. For instance, Lara was initially reluctant to using modelling writing exercises, for instance matching sentences in daily language and mathematical language ('graph language') with segments of the graph, resulting in a target text. Initially, she felt resistance against this approach because of its pre-determined character, which she would normally not allow in her mathematics lessons. Later on, however, she acknowledged the fact that learning mathematics was different from learning (in) a second language and thus different pedagogical approaches were required. As a consequence, she started to adopt a different attitude towards writing in mathematics lessons. We derived changes in beliefs from statements as:

Yes, I do think writing is very important because it forces you to put your thoughts into words. And that process is actually a matter of understanding. For the domain of line graphs a beautiful scaffold can be constructed for the children [refers to the writing plan that helps students to describe each segment of the graph]. So then they can write a text by themselves and it does not matter if that is time-consuming.

An example of a reported growing awareness related to scaffolding language in mathematics education is:

And I notice, when I read [key publications on scaffolding], that I keep thinking 'oh yes, indeed' and then I say to myself: thinking 'oh yes, indeed' actually means that you [I] haven't been performing these scaffolding strategies up to now.

Within the same theme, Lara also reported on changes in beliefs, as in her saying that reformulating students' utterances into more academic wordings, although initially not her style, actually seemed to work really well. For this category, Lara's growing knowledge could mainly be 
derived from many statements in which she spoke about scaffolding in an increasingly differentiated way. Reflecting upon learning how to scaffold language, Lara declared:

It's like learning a new profession. There are so many optional scaffolding strategies and, well, it is hard to actually choose the right one in a particular situation. You cannot acquire this ability very easily. Yet I do think this is very important. That is why I would argue for professionalising primary teachers on scaffolding.

These utterances support our initial assumption that awareness is interrelated with knowledge, beliefs and intentions: the teacher needs to not only have the intention to scaffold and believe that it works, but also know how to apply which strategy and when.

The most notable change in the category students' language development and participation concerns Lara's view on multilingual students' participation in mathematics lessons. This view reveals a growing awareness of students' hidden linguistic incompetence.

This development can be derived from statements as:

I have never noticed multilingual students to fall off track. (post1)

You need to give these children [multilingual students] something extra, because, well, a native-speaking child does not need to get exposed to all these words and concepts to be able to participate. (post2)

Another new belief was the conviction that all children-in particular second language learners-should be encouraged to actively participate in mathematics lessons, by producing both oral and written language. This belief is in line with the premise of content-based language instruction that language production is a prerequisite for fully participating in all areas of the curriculum.

\subsection{To what characteristics of dual design research can Lara's learning process be attributed?}

Of all characteristics we asked Lara to rate (on a 1-5 scale), there were two aspects which she rated as 3 (the lowest rating she gave): (a) predicting how a particular activity would support a learning goal and (b) writing reflective notes. In the verbal part of the interview, she explained the former as being a matter of difficulty: she considered it difficult to predict students' linguistic development. She further explained that writing reflective notes did not specifically add to her learning process, because she already "used to think about these same issues in the past".

Lara did value highly some aspects that were typical for dual design research as enacted in this study (score 4 or 5).
In the first place, she mentioned the feedback she was given by the researchers throughout both teaching experiments. Examples included feedback on her increased use of supporting gestures while explaining, as well as feedback related to asking only one question at the time. In the second place, Lara attached great value to the interventionist character of the teaching experiments: lesson plans were never written 3 weeks in advance, but often adapted and restructured at the last minute. In her role of codesigner-as she stated to have perceived it-Lara appreciated the fact that lessons plans "became her own". She explicitly mentioned the importance of looking back on a given lesson and reflecting on the instructional activities. The stimulated recall interviews served to observe and analyse in more detail students' participation as well as her own role. As she formulated it: "I can see what I do and what I don't do, as well as on what aspects I am focusing and not focusing." Contributing to the practical elaboration of different forms of scaffolding made her more aware, Lara said, referring to designed scaffolding strategies that promoted students' independence (such as writing plans) as being different from interactional scaffolding strategies (e.g. reformulating students' answers or asking them to be more precise linguistically). Finally, she considered the cyclic character of great importance. It was only due to revising lessons from the first teaching experiment and enacting them in the second, Lara declared, that she managed to help children reach a higher linguistic level and that she managed to use meta-language (talk about language) as an important interactional scaffold. The following paragraph will provide an example that illustrates the benefit of the crucial aspects of dual design research.

\subsection{An example illustrating the teacher's learning process in dual design research}

As an illustration of Lara's learning process we present an example of how she learnt to use the 'expanding' word list for subject-specific words as a designed scaffolding strategy. In the lesson plans, all relevant words for each lesson were included, and suggestions were made as to which parts of the lesson were suitable for introducing particular words (e.g. axes, increase, gradually). Lara was asked to add these words to the word list when discussing them in whole-class situations. Furthermore, she was asked to refer to these words, either verbally or by pointing at them, once they re-occurred in whole-class discussions. In addition, she was asked to encourage students to use the word list as support for speaking and writing mathematically.

Before the third lesson of the first teaching experiment, we asked Lara to introduce the word list. However, in the third and fourth lesson, Lara hardly managed to use the word list. We discussed this with her after each lesson, 
referring to particular lesson episodes that would have been suitable for adding crucial subject-specific words to the list and discussing them. We also encouraged her to combine the word list with the interactional scaffold of asking students to be more precise. For instance, for a student saying "vertical line", we suggested that Lara ask: "How do we say that in mathematical language?" Then, 'vertical axis' could be added to the word list. From the fifth lesson on, Lara only occasionally managed to use the word list in whole-class discussions.

In the stimulated recall interviews used in the second teaching experiment, we asked Lara to respond to video fragments showing missed and exploited opportunities for word list use. We always started these interviews by posing neutral questions to promote Lara's own reflection. After watching video fragments, we would ask her for instance: "What do you think is happening here?" Increasingly, Lara mentioned the missed opportunities herself. In addition, we provided Lara with feedback on what we observed. For instance, after lesson one, we mentioned that Lara had added words to the word list while students were doing group work, hence without students noticing the addition of words.

In the first four lessons in the second teaching experiment, Lara again experienced difficulty with using the word list. After lesson two, Lara stated that she just did not manage to add words during discussions, but that she could not explain why. However, after the first few lessons of the second experiment, she repeatedly stated that she agreed with the word list's potential. Only after lesson three did Lara finally point out why she could not use the word list as a scaffolding strategy: she struggled with simultaneously promoting mathematical learning and paying attention to the related language. In response to Lara struggling to pay attention to both mathematical learning and language development, one of the researchers explained after lesson three that the development of mathematical concepts and mathematical language are intertwined. Lara seemed very sensitive to this argument and again declared her intention to start using the word list more actively.

She did indeed do so from the fourth lesson of the second teaching experiment onwards. In a report reflecting on lesson four, she wrote that she had repeatedly paid attention to those mathematical words that were already on the list and stated: "I think that most of these concepts have really sunk in now!" After the sixth lesson, Lara declared that mathematical language should not be taught in an isolated way. Although we discussed this issue with Lara earlier, this awareness now seemed a view of her own that she wanted to enact in her teaching. Finally, after lesson seven, Lara stated having mastered the scaffolding strategy of using the word list: "It is now in my system. I don't know why I couldn't do it; it really suits me now."
In sum, the lesson plans were not sufficient support for Lara to actually use the word list as a scaffolding strategy. The dual design research setting, which involved cycles of prediction, feedback and reflection by both the teacher and the researchers, helped her see the need and value of such strategies as well as how to perform them. From the video analysis, we can infer that her development comprised three phases: (1) writing words when they occurred in classroom discussions, (2) referring to the word list (verbally or by gesturing) and (3) promoting students' use of the word list. Towards the end of the second teaching experiment, we observed an increasing number of students using the word list as a means of support when reasoning out aloud.

In terms of scaffolding characteristics, these phases signify firstly the temporal nature of scaffolding. Secondly, expressing the intention to perform the word list scaffolding strategy indeed resulted in its enactment. Thirdly, the responsive nature came increasingly to the fore in later lessons. For instance, when students were struggling to formulate a graph description, Lara sometimes only needed to point at the word list, which was just enough support for them to produce a mathematically and linguistically correct graph description. This pointing at the word list was repeatedly discussed during stimulated recall interviews.

\section{Discussion}

The present study aimed to shed light on a mathematics teacher's learning process in a dual design research setting. In answer to the first research question, the teacher's reported and derived learning outcomes indicate an increasing awareness of the importance of language development in mathematics lessons, an increasing frequency and variety of intentions to scaffold language, and a growing awareness of the linguistic struggles of multilingual students, hence the necessity to perform scaffolding strategies. Increasing knowledge of scaffolding language was derived from statements throughout the interviews.

In answer to the second research question, the teacher attributed her learning to many characteristics of how we shaped dual design research: the cyclic and interventionist character, her co-designer's role, the stimulated recall interviews that promoted reflection and the feedback she received from the researchers. In terms of the learning activities (Sect. 2.4), she particularly valued experimenting, interaction with the researchers and reflection. The overall conclusion from the analysis is that the dual design research setting promoted the development of the teacher's knowledge and beliefs with regard to scaffolding, but also fostered changes in practice and intentions for practice. 
In summary, we argue that dual design research is a valuable way of developing particular innovative expertise. Once there is a solid empirical and theoretical basis on a topic, other, more efficient ways to develop this expertise at larger scales should be deployed. In the remainder of this section, we therefore discuss how our findings could be "generalised" to professional development at a larger scale. To this end, we first need to raise two points.

The first point is that statistical generalisation is not possible here. As in other types of qualitative research, design research aims to gain insights into mechanisms, acknowledging their dependence upon the social and cultural contexts in which these mechanisms operate (Maxwell, 2004). Using an example of Lara's learning, we mention the underlying mechanisms that we think can be drawn on in subsequent cycles of dual design research (analytic generalisation).

Lara repeatedly stated experiencing a field of tension between mathematics and language. We observed her struggling with finding a way to use language functionally and to perform scaffolding. For example, only in one of the later lessons of the second teaching experiment did she express the view that key concepts should be discussed while dealing with mathematical content, and thus not be explained in a vocabulary-teaching way. Lara at that time seemed to have developed the awareness that two foci (Mason, 1998) are needed to realise scaffolding: attention to mathematics and attention to language simultaneously. Mason's claim that awareness is a prerequisite for learning is substantiated by the fact that Lara soon after did indeed finally manage to functionally-and naturally-use the word list in her lessons. The mechanisms underlying this growing awareness are presumably first that Lara was constantly challenged to reflect on her actions, to make her thinking-in-action explicit, and to formulate how instructional activities and scaffolding strategies would support students' learning processes. Second, the stimulated recall interviews provided her with feedback, making her aware of "blind spots" in her teaching.

The second point we need to make is that our dual design research has yielded not only knowledge of Lara's learning process, but also theory and instructional activities on scaffolding language in mathematics education, in the form of a conceptual framework of scaffolding strategies, empirically tested prototypical lessons, and video footage and transcripts of how different strategies can be enacted. A new teacher could therefore draw on resources that we did not yet have available when starting to work with Lara.

These two points help to sketch a route towards upscaling scaffolding expertise among larger groups of teachers. We have already taken the first step of this route: in a next teaching experiment, we worked with another teacher with less teaching experience than Lara and with no prior knowledge of scaffolding. Some characteristics of our dual design research setting, such as stimulated recall interviews, were maintained, but we did not involve her in co-design for efficiency reasons. Yet the new teacher learnt to perform scaffolding strategies at least as fast as Lara. We explain this by referring to the two aforementioned points. In this next teaching experiment, we could build on the resources coming out of the first dual design research cycles such as the resulting framework of scaffolding strategies and concrete examples. Furthermore, our insights into the mechanisms that promoted Lara's learning helped us support the new teacher more efficiently.

The second step is to use the products and insights from our research in a 'next' level of dual design research: a professional development course is designed in collaboration with a teacher educator (or Lara) to promote mathematics teachers' scaffolding expertise. Because of the innovative nature of this next level of dual design research, we envision that intensive methods such as co-design are necessary. This first dual design research cycle would yield both knowledge of the teachers' learning and the means to support that learning and the teacher educator's learning necessary to facilitate that learning. Again, a second cycle would be less labour intensive and a "train the trainer" model can be used for further scaling up the development of teachers' expertise.

Acknowledgments We gratefully acknowledge the teacher for her committed participation in this dual design research project. We also thank Koeno Gravemeijer and Jan van Maanen for helpful suggestions and Nathalie Kuijpers for editing the English text. The research reported in this paper was funded by the Freudenthal Institute for science and mathematics education, Utrecht University.

Open Access This article is distributed under the terms of the Creative Commons Attribution Noncommercial License which permits any noncommercial use, distribution, and reproduction in any medium, provided the original author(s) and source are credited.

\section{References}

Bakkenes, I., Vermunt, J. D., \& Wubbels, T. (2010). Teacher learning in the context of educational innovation: Learning activities and learning outcomes of experienced teachers. Learning and Instruction, 20, 533-548.

Ball, D. L., Thames, M. H., \& Phelps, G. (2008). Content knowledge for teaching: What makes it special? Journal of Teacher Education, 59, 389-407.

Brinton, D., Snow, M. A., \& Wesche, M. (2003). Content-based second language instruction. Michigan: Michigan Classics Edition.

Brown, A. L. (1992). Design experiments: Theoretical and methodological challenges in creating complex interventions in classroom settings. The Journal of the Learning Sciences, 2, 141-178.

Campbell, A. E., Adams, V. M., \& Davis, G. E. (2007). Cognitive demands and second-language learners: A framework for 
analyzing mathematics instructional contexts. Mathematical Thinking and Learning, 9, 3-30.

Cicchetti, D. V. (1976). Assessing inter-rater reliability for rating scales: Resolving some basic issues. British Journal of Psychiatry, 129, 452-456.

Cobb, P. (2000). Conducting teaching experiments in collaboration with teachers. In A. E. Kelly \& R. Lesh (Eds.), Handbook of research design in mathematics and science education (pp. 307-333). Mahwah, NJ: Lawrence Erlbaum.

Cobb, P., Confrey, J., diSessa, A. A., Lehrer, R., \& Schauble, L. (2003). Design experiments in educational research. Educational Researcher, 32, 9-13.

Cobb, P., Zhao, Q., \& Dean, C. (2009). Conducting design experiments to support teachers' learning: A reflection from the field. The Journal of the Learning Sciences, 18, 165-199.

Collins, A. (1992). Toward a design science of education. In E. Scanlon \& T. O'Shea (Eds.), New directions in educational technology (pp. 15-22). New York: Springer.

Gibbons, P. (2002). Scaffolding language, scaffolding learning: Teaching second language learners in the mainstream classroom. Portsmouth, NH: Heinemann.

Gibbons, P. (2009). English learners academic literacy and thinking. Portsmouth, NH: Heinemann.

Graeber, A., \& Tirosh, D. (2008). Pedagogical content knowledge: Useful concept or elusive notion. In P. Sullivan \& T. Wood (Eds.), The international handbook of mathematics teacher education. Knowledge and beliefs in mathematics teaching and development (Vol. 1, pp. 117-132). Rotterdam/Taipei: Sense Publishers.

Gravemeijer, K. P. E., \& Cobb, P. (2006). Design research from a learning design perspective. In J. van den Akker, K. P. E. Gravemeijer, S. McKenney, \& N. Nieveen (Eds.), Educational design research (pp. 45-85). London: Routledge.

Gravemeijer, K. P. E., \& Van Eerde, H. A. A. (2009). Design research as a means for building a knowledge base for teachers and teaching in mathematics education. Elementary School Journal, 109, 510-524.

Jaworski, B. (1998). Mathematics teacher research: Process, practice and the development of teaching. Journal of Mathematics Teacher Education, 1, 3-31.

Ling Lo, M., Marton, M. F., Fai Pang, M., Yan Pong, W., et al. (2004). Toward a pedagogy of learning. In F. Marton \& A. Tsui (Eds.), Classroom discourse and the space of learning (pp. 189-225). Mahwah, NJ: Lawrence Erlbaum Associates.

Mason, J. (1998). Enabling teachers to be real teachers: Necessary levels of awareness and structure of attention. Journal of Mathematics Teacher Education, 1, 243-267.

Mason, J. (2010). Attention and intention in learning about teaching through teaching. In R. Leikin \& R. Zazkis (Eds.), Learning through teaching mathematics (pp. 23-47). New York: Springer.

Maxwell, J. A. (2004). Causal explanation, qualitative research, and scientific inquiry in education. Educational Researcher, 33(2), $3-11$.
Meijer, P. C., Zanting, A., \& Verloop, N. (2002). How can student teachers elicit experienced teachers' practical knowledge? Tools, suggestions and significance. Journal of Teacher Education, 53, 406-419.

Moschkovich, J. N. (2002). A situated and sociocultural perspective on bilingual mathematical learners. Mathematical Thinking and Learning, 4, 189-212.

Norton, A. H., \& McCloskey, A. (2008). Teaching experiments and professional development. Journal of Mathematics Teacher Education, 11, 285-305.

Potari, D., \& Jaworski, B. (2002). Tackling complexity in mathematics teaching development: Using the teaching triad as a tool for reflection and analysis. Journal of Mathematics Teacher Education, 5, 351-380.

Revans, R. W. (1982). The origins and growth of action learning. Bromley: Chartwell-Bratt Ltd.

Ropo, E. (2004). Teaching expertise. In H. P. A. Boshuizen, R. Bromme, \& H. Gruber (Eds.), Professional learning: Gaps and transitions on the way from novice to expert (pp. 159-179). Dordrecht: Kluwer.

Roth, W.-M., Tobin, K., \& Zimmermann, A. (2002). Coteaching/ cogenerative dialoguing: Learning environments research as classroom praxis. Learning Environments Research, 5, 1-28.

Shulman, L. S. (1987). Knowledge and teaching: Foundations of the new reform. Harvard Educational Review, 57(1), 1-22.

Simon, M. A. (1995). Reconstructing mathematics pedagogy from a constructivist perspective. Journal for Research in Mathematics Education, 26, 114-145.

Simon, M. A. (2000). Research on the development of mathematics: The teacher development experiment. In A. E. Kelly \& R. A. Lesh (Eds.), Handbook of research design in mathematics and science education (pp. 335-359). Mahwah, NJ: Lawrence Erlbaum Associates.

Stigler, J. W., \& Hiebert, J. (1999). The teaching gap. Best ideas from the world's teachers for improving education in the classroom. New York: The Free Press.

Van den Boer, C. (2003). Als je begrijpt wat ik bedoel. Een zoektocht naar verklaringen voor achterblijvende prestaties van allochtone leerlingen in het wiskundeonderwijs [If you know what I mean. A search for an explanation of lagging results of mathematics education among ethnic minority students]. Utrecht: CDBeta Press.

Van Eerde, H. A. A., \& Hajer, M. (2009). The integration of mathematics and language learning in multiethnic schools. In M. César \& K. Kumpulainen (Eds.), Social interactions in multicultural settings (pp. 269-296). Rotterdam/Taipei: Sense Publishers.

Verloop, N., Van Driel, J., \& Meijer, P. C. (2001). Teacher knowledge and the knowledge base of teaching. International Journal of Educational Research, 35, 441-461.

Wood, D., Bruner, J., \& Ross, G. (1976). The role of tutoring in problem solving. Journal of Child Psychology and Psychiatry, $17,89-100$. 